\title{
混合像元的因子分析方法及其在大范围 冬小麦播种面积估算中的应用探讨
}

\author{
徐希㵢 周莲芳 朱晓红
}

（北京大学遥感技术应用研究所）

\section{关链词混合像元、因子分析、冬小麦播种面积估算}

由于众所周知的原因, 依靠逐级层层上报的统计数据是不可能获得准确的冬小麦播种面 积数据的, 所以人们曾寄希望于借助遥感手段去解决问题. 然而一个基本困难是: 冬小麦的 主要生长期仅一百余天, 在这样短的生长期内, 如果依靠地面分辨率较高的 TM 或 SPOT 卫 星数据, 那么由于它们的重复周期较长, 不可能覆盖象一个省那样大的范围, 只能获得个别地 区的图像, 因而失去了它的实际意义. 而 NOAA-AVHKR 卫星资料虽然重复周期短、覆盖面 积大, 然而它的地面分辨率太低, 所以用现行的一般图像处理方法欲从 AVHRR 资料中获取 准确的冬小麦播种面积是很困难的. 妨碍 AVHRR 资料在快速环境监测方面广泛应用的基 本困难有两个方面: 一是低分辨率带来的混合像元问题, 二是卫星遥感器姿态上的正直视与 斜视同时并存所带来的应用模式的复杂性.

本文的目的是通过应用低分辨率、多时相的 AVHRR 资料推算河南全省当年冬小麦播种 面积的方法研究, 为从混合像元中提取专题信息提供一个新方法. 为避免多视角所带来的复 杂性, 在选择资料上我们暂时将视角限制在 $30^{\circ}$ 以内.

\section{一、光谱参数的选择}

有两类典型的植被光谱参数: 植被垂直指数 $(P V I)$ 与绿度 $(G) . P V I$ 具有较好的滤 除土壤背景信息的能力, 并且受大气影响较小 ${ }^{[1]}, G$ 则对植被的叶面积指数 $(L A I)$ 反应灵 敏 ${ }^{[2]}$. 如果选择红光与近红外光两个波段的反射率为典型代表, 那么: $P V I=\rho_{I R} \cos \dot{\theta}-$ $r_{R} \sin \theta, G=\rho_{I R} / \rho_{R}$, 其中, $\rho_{I R}, \rho_{R}$ 分别表示近红外波段与红光波段的反射率. 在 $\rho_{I R}-\rho_{R}$ 坐标系中, 土壤迥归线与 $\rho_{R}$ 轴的夹角为 $\theta .1987$ 年作者在河南省实测了各种地物的 $P V I$ 值 与 $G$ 值随时间的变化曲线并分别示于图 1 和图 2 .

我们最终选择 PVI 为因子分析的基本光谱参数形式. 原因在于:（1）从冬小麦返青到 抽穗期,冬小麦、油菜、道路等各自有其特殊的 PVI-t 曲线,易于区别; 而同一时期内冬小麦与 油菜的 $G$ 值相互混济, 不可区分. 冬小麦抽穗期以后, 各类地物的 $P V I$ 值相互交迭,因此估算 冬小麦播种面积应以抽穗以前的遥感资料为基础.' (2) PVI 参数形式具有线性可加性. 就. 是说, 设某一混合像元中包括有 $N$ 种地物, 它们各自的 $P V I$ 值可用 $(P V I)$. 表示, 那么混合 像元的总 $P V I$ 值应为:

本文 1988 年 8 月 9 日收到. 1988 年 10 月28日收到修改稿. 


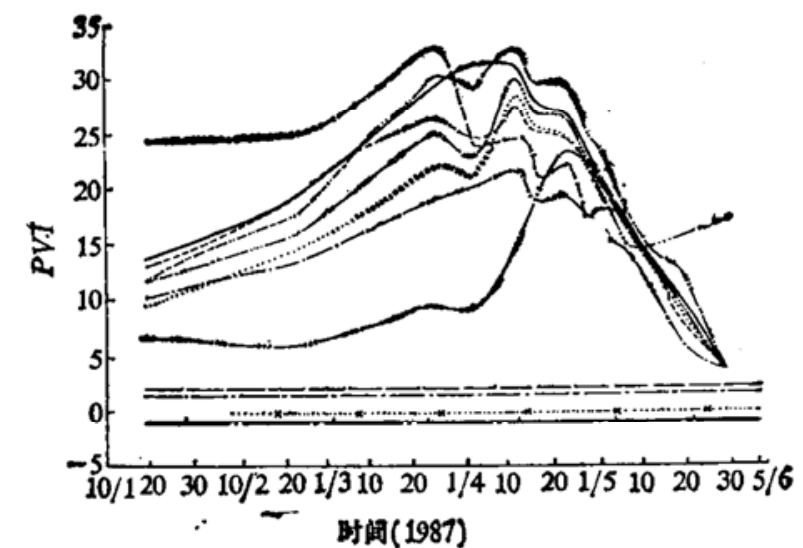

图 $1 P V I$ 随 $t$ 变化曲线

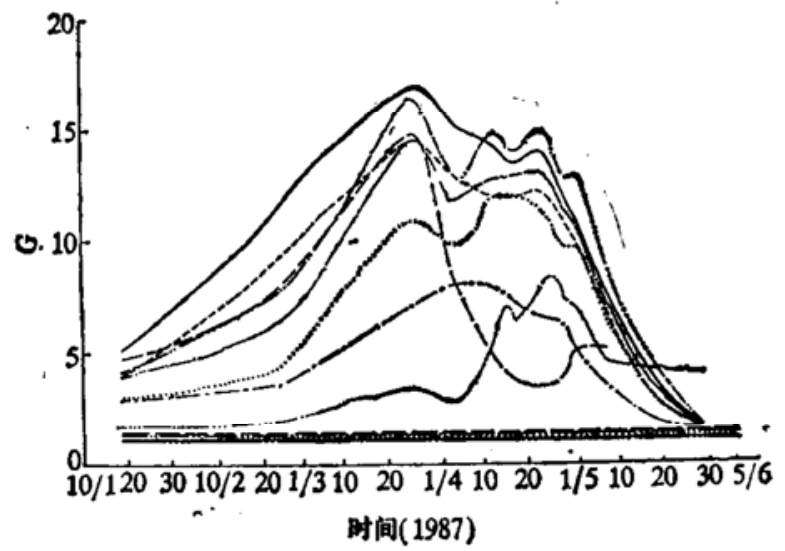

图 $2 G$ 随 $t$ 变化曲线

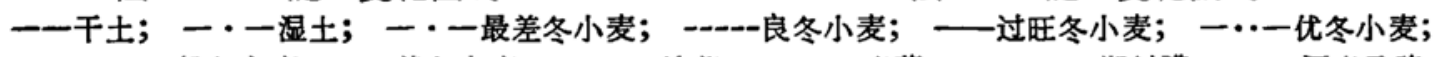

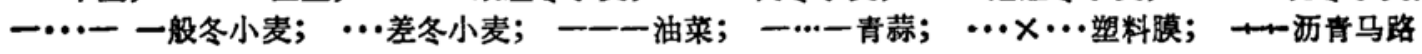

$$
P V I=\sum_{n=1}^{N} a_{n}(P V I)_{n},
$$

其中 $a n$ 代表第 $n$ 种地物在混合像元中所占的面积百分比; 相比之下, 光谱参数 $G$ 不具有线性 可加性,而线性可加性是应用因子分析方法分解混合像元的前提条件. (3) 大气效应在 PVI 参数形式下受到抑制, 而参数 $G$ 对大气效应反应灵敏.

\section{二、从混合像元中分离冬小麦播种面积信息的因子分析方法}

设由 NOAA-AVHRR 扫描河南全省共获得 $M$ 个像元, 在冬小麦返青到抽穗期间共获得 $T$ 次 AVHRR 资料,每次可根据 AVHRR 的第一通道与第二通道的数据逐个像元算得 $P V I$ 值,并用 $(P V I)_{i, j}$ 表示之. 脚标 $i$ 表示像元的几何位置码, $i$ 表示时间序列码. 由此诃以构 成资料数据矩阵 $|D|$ :

从物理分析出发:

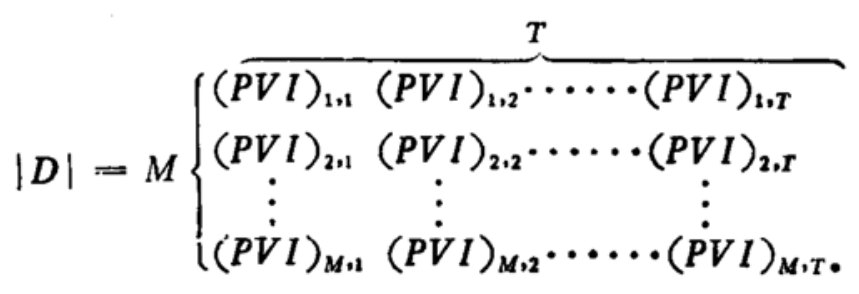

$$
(P V I)_{i, j}=\sum_{n=1}^{N} a_{i, n}(P V I)_{n, i} .
$$

由于每一混合像元中某种地物所占的面积比是不随时间变化的, 而每一种地物的 PVI 值只随 时间而变,因此:

其中

$$
|D|=|A||(P V I)|,
$$

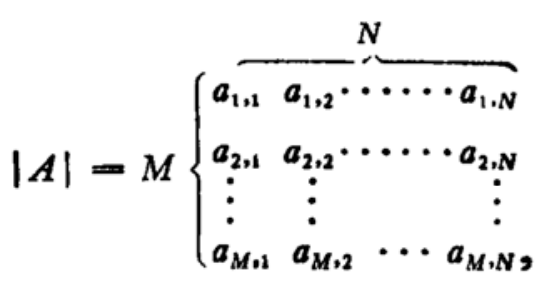


䂧 $|A|$ 为面积矩阵.

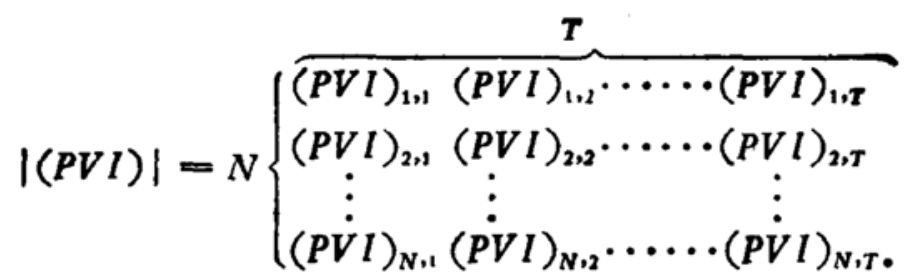

光谱参数矩阵 $|(P V I)|$ 只是时间函数矩阵, 可以通过野外光谱测定获得. $|D|$ 为已知 资料矩阵. 由于一般说来 $|(P V I)|$ 不是方阵, 也不满足“满秩”的条件, 所以不能通过 (1)式 两边同时右乘 $|(P V I)|^{-1}$ 而获取 $|A|$ 矩阵. 因此只有通过对 $|D|$ 进行一般经验正交函数 展开,使 $|D|$ 分解为抽象的空间函数矩阵 $|R|$ 和抽象的时间函数矩阵 $|C|$ 之积, 然后通过. 转换矩阵 $|T|$ 求得 $|A|$ 矩阵. 其过程简述如下:

$|D|$ 矩阵是一个 $M \times T$ 维的时-空矩阵, 可应用一般因子分析方法进行分解, 使时-空函 数分离. 令 $|Z|=|D|^{T}|D|$, 其中 $|D|^{T}$ 为 $|D|$ 的转置矩阵, $|Z|$ 为一个 $T \times T$ 维的协方 差矩阵, 对 $|Z|$ 进行对角化运算, 可获得一系列的本征值 $\lambda_{i}$ 与相应的本征矢量 $Q_{i}$ ( $i$ 可由 1 增 至 $T$ ). 由一系列本征矢量 $Q_{i}$ 可构成本征矩阵 $(Q)$, 本征矩阵的转置矩阵和逆矩阵相等, 即 $|Q|^{T}=|Q|^{-1}$, 则: $|Q|^{-1}|Z||Q|=|Q|^{-1}|D|^{T}|D||Q|=|Q|^{T}|D|^{T}|D||Q|$; 如令 $|R|=$ $|D||Q|$, 则 $|Q|^{-1}|Z||Q|=|R|^{T}|R|,|D|=|R||Q|^{T}$; 如令 $|C|=|Q|^{T}$, 则

$$
|D|=|R||C| \text {. }
$$

(2) 式表明, $|D|$ 可以表达为抽象的空间函数矩阵 $|R|$ 与抽象的时间函数矩阵 $|C|$ 之矩阵 积.

引人转换矩阵 $|T| .|T|$ 应是一个方阵, 而且 $|T|^{-1}|T|=1$, 则

$$
|D|=|R||T|-|T||C| \text {. }
$$

比较(1)式与(3)式, 可令 $|T||C|-|(P V I)|$, 其中 $|T|$ 为待求的矩阵, 是由一系列矢量 $T_{n}$ 构成的, 而 $T_{n}=|\lambda|^{-1}|C|^{T}(P V I)_{n}$, 详见文献[3], 由此可以算得 $|T|$, 则 $|A|=|R| \times$ $|T|^{-1}$.

这表明, 如果 $|(P V I)|$ 矩阵中第 $n$ 行代表冬小麦的 $(P V I)$ 值随时间变化的特征, 那么 面积矩阵 $|A|$ 中相应的第 $n$ 列即为冬小麦在混合像元中所占的面积比例. 在获得每一个像元 的几何尺寸之后,便可以推算出实际的冬小麦播种面积了.

\section{三、结果与分析}

作者应用 AVHRR 资料逐县计算了 1987 年河南全省冬小麦的播种面积, 为了验证其精 确度,选择河南省长葛县同时用 AVHRR 和 TM 资料进行估算, TM 的结果按 AVHRR 的 像元尺度取平均值并量化为 10 个等级, 然后逐像元进行量化等级比较, 其结果列于图 3. 图 中注在统计点旁边的数字为重迭的像元数, 坐标值均为冬小麦播种面积在单个像元中所占的 面积比.

结果表明: (1) AVHRR 与 TM 的结果趋势一致, 证明原则上该种方法是可行的, 与 $\mathrm{TM}$ 的结果相比, 相关系数为 0.800 . 误差来源主要是 AVHRR 的扫描姿态所引起的像元不 能严格配准, 以及遥感器的正直视与斜视并存, 虽然我们采取了限制性措施, 但仍不能很好地 消除误差. (2) AVHRR 的结果对 TM 有一个系统偏高, 原因在于传统概念上的冬小麦面积 


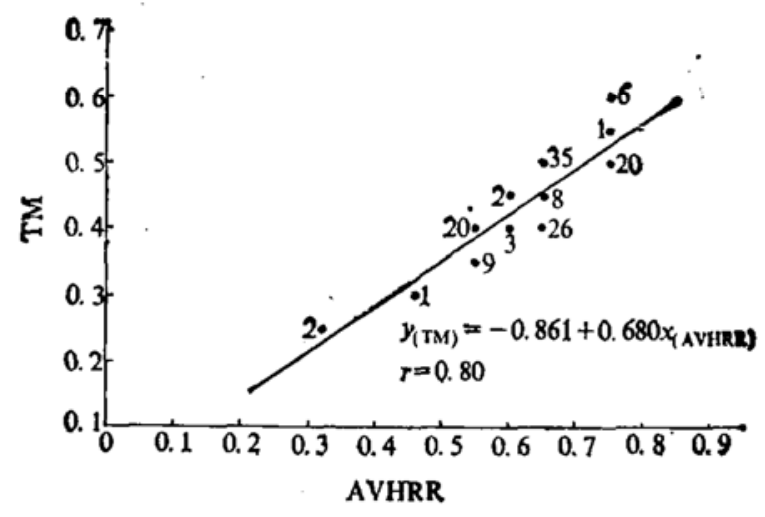

图 3 TM与 AVHRR 逐像元对比

包括了麦田行间裸露地, 而其光谱与植被相差较高, 与田埂、乡间道路以至村庄等相仿. 因此 依靠光谱值来进行因子分解时只能把它归入非小麦用地,这就使得 TM 的结果偏低. (3) 对 . 一地势起伏较大的深山区, 误差有所增大, 其原因是起伏的地势会带来阴影等一系列新问题.

\section{四、结论}

（1）混合像元问题是遥感定量分析中不可迴避的问题，也是一个基本难题，虽然提高遥感 器的地面分辨率可以在某些应用问题上使这一矛盾得到缓解，但对定量分析仍无济于事. 混 合像元的大量存在也是所谓“同物异谱”以及“异物同谱”现象的根源之一. 本文应用经验正交 函数的方法从 AVHRR 的混合像元中提取专题信息, 为解决这一难题做了初步尝试, 虽因 NOAA 系统自身的扫描特征使其精度还不足以应付实用需要,但它仍无可怀疑地证明了这一 方法在原理上的可行性.

(2) 为使遥感技术能深人到环境监测的领域中, 90 年代新一代的遥感器将具有新的特 点. 如 JPL 为陆地资源卫星设计的 HIRIS 具有多通道和多视角, 以图缩短重复周期, 在 0.4-2.5 $\mu \mathrm{m}$ 之间通道数达 168 个,却保留了 $\mathrm{TM}$ 原有的 $30 \mathrm{~m} \times 30 \mathrm{~m}$ 的地面分辨率. 因此,需 要探索适应新一代遥感资料的处理方法. 由于多时相与多频道在处理方法上是等价的, 所以 NOAA-AVHRR 资料可以充当探索新方法的实验品. 尤其对第三世界来说这很重要. 事实 上, 法国在 SPOT 卫星施放前, Cracknell, A. P. 等人已经通过研究 AVHRR 资料的斜视 问题,为 SPOT 做了前期可行性研究 ${ }^{[4]}$. 所以，本文的意义不仅在于讨论大面积冬小麦播种 面积估算本身,亦在于指出重视 NOAA-AVHRR 资料处理方法的研究有何种意义.

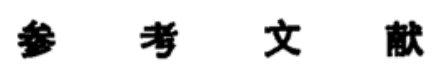

[1] 徐希政等, 内蒙古草场资源䧟感应用研究, 1: 123-135.

[2] 徐希而等,地理学报, 40(1985), 4: 333-346.

[3] Malinowski, E. R., Factor Analysis in Chemistry, International Text Book Company, 1982, $50-54$.

[4] Singh, S. M. and Cracknell, A. P., Inter. J. R. S., 67(1986), 3: 361-377. 